\title{
Stage Two Milk Fever in a Dairy Cow: A Case Report
}

\author{
*Faez Firdaus Jesse Abdullah ${ }^{1,3}$, Abdinasir Yusuf Osman ${ }^{1,2}$, Yusuf Abba ${ }^{2,4}$, \\ Lawan Adamu ${ }^{1,4}$, Konto Mohammed ${ }^{1,4}$, Abdulnasir Tijjani ${ }^{2,4}$, Anis Athira \\ Mauli $^{1}$, Abdul Aziz Saharee ${ }^{1,3}$, Abdul Wahid Haron ${ }^{1,3}$ \\ ${ }^{I}$ Department of Veterinary Clinical Studies, Faculty of Veterinary Medicine, University Putra Malaysia, 43400 \\ UPM Serdang, Selangor, Malaysia \\ ${ }^{2}$ Department of Veterinary Pathology and Microbiology, Faculty of Veterinary Medicine, University Putra \\ Malaysia, 43400 UPM Serdang, Selangor, Malaysia \\ ${ }^{3}$ Research Centre for Ruminant Disease, Faculty of Veterinary Medicine, University Putra Malaysia, 43400 \\ UPM Serdang, Selangor, Malaysia \\ ${ }^{4}$ Faculty of Veterinary Medicine, University of Maiduguri, PMB1069, Borno State, Nigeria
}

\begin{abstract}
The biological cycles of milk production and reproduction determine dairy profitability thus making management decisions dynamic and time-dependent. Metabolic diseases pose significant risk on net earnings of a dairy enterprise. We report a case of clinical hypocalcaemia (milk fever). A 7-year-old Jersey cross cow weighing $500 \mathrm{~kg}$ was presented with left lateral recumbency with the neck curved towards the flank. The case history indicated that the animal had calved two months ago and was semi-intensively managed. There was no history of vaccination and deworming. The daily production of milk was about 13 liters. Physical examination revealed the temperature and pulse rate were within the normal range, but there was increased in respiratory rate and a dehydration status of 5\%. Upon auscultation of the heart, there was decreased in intensity of the heart sound. The patient was diagnosed with milk fever and treatment was done by slowly infusing $400 \mathrm{~mL}$ of Calcium borogluconate into the jugular vein over a period of 10-20 minutes. Intravenous infusion of $2000 \mathrm{~mL}$ $0.9 \% \mathrm{NaCl}$ and $1000 \mathrm{~mL}$ of $5 \%$ Glucose were instituted in order to restore blood glucose level and to correct the dehydration. The animal recovered after the treatment, thus the prognosis was good.
\end{abstract}

Keywords: milk fever, calcium, prognosis, dehydration

\section{Introduction}

Milk fever is a metabolic disease of mature dairy cows that occur just before or soon after calving. The clinical signs include muscle weakness, cold skin due to peripheral circulatory failure, small amplitude pulse, decreased intensity of heart sounds, lateral recumbency and drowsiness [1,2]. According to [3], the factors that contribute to occurrence of milk fever are parturition, stage of lactation, age, breed and diet. [4] had stated that number of parity also play an important role in milk fever. Three stages of milk fever are recognized based on the clinical presentation of the animal. In stage one, the cow able to stand but staggers due to weakness of the muscle. In stage two, the cow is on sterna recumbency with twisting or curving of the neck towards the flank, while in stage three, the cow suffers from paralysis leading to coma and death [5]. Stages one and two are easily managed, while stage three may warrant culling of the animal. Milk fever is managed by a slow intravenous infusion of calcium borogluconate into the jugular vein. Lowering dietary calcium levels during dry period is very important for prevention of milk fever, as well as to balance the acid-base diet ratio; Dietary Cation-Anion Difference (DCAD) [6]. High milk producing cows are more prone to milk fever due to the high demands in calcium, resulting to metabolic disease in dairy cows. The incidence of milk fever is higher during calving and can extend to the peak of lactation which is in week 6 to 8 post partum [5]. According to [7], cows that recover from milk fever are prone to other metabolic disease. Similarly, cows that have suffered from milk fever are more likely to develop the condition during subsequent calving [8]. The prognosis of milk fever depends on the stage of the condition; stage 1 is less severe and the animal is able to stand but staggering. In stage 2, the cow is recumbent on sterna recumbency, while in stage 3 , there is progressive muscular paralysis that may lead to coma and death if prolonged [5]. This report aims to highlight the management of type II milk fever in a cow.

\section{Case Report}

A 7 year old Jersey cross dairy cow weighing $500 \mathrm{~kg}$ was presented to the large animal unit of University Teaching Hospital, Universiti Putra Malaysia with a complaint of prolonged recumbency, weakness and inappetance. The animal had calved 2 months ago and is managed semi intensively on grass, dairy pellet, brew by-product and oil palm by-product. Vaccination and deworming status was unknown. Physical examination showed the vital parameters were within the normal range. However, upon auscultation of the heart, there was a decreased intensity of the heart sound. The cow was on left lateral recumbency with the neck 
curved towards the right flank (S-shaped) (Fig.1). There was 5\% dehydration. The differential diagnoses were; milk fever, hypoglycemia and metabolic acidosis. A tentative diagnosis was made based on the history of the cow being high milk producing animal, inappropriate nutritional management and the presented typical clinical features of milk fever.

Management of the case involved instituting Calciject $40 \mathrm{CM} ®$ containing calcium borogluconate, 400 $\mathrm{mL}$ slowly, intravenously in order to restore blood calcium level. Intravenous infusion of $2000 \mathrm{~mL} 0.9 \% \mathrm{NaCl}$ and $1000 \mathrm{~mL} 5 \%$ Glucose was instituted with an aim to restore blood glucose level and to correct the dehydration.
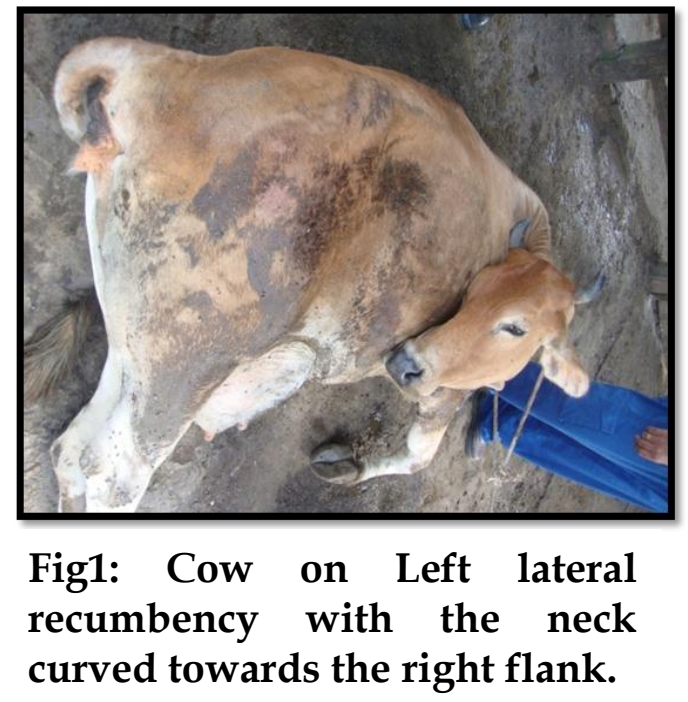

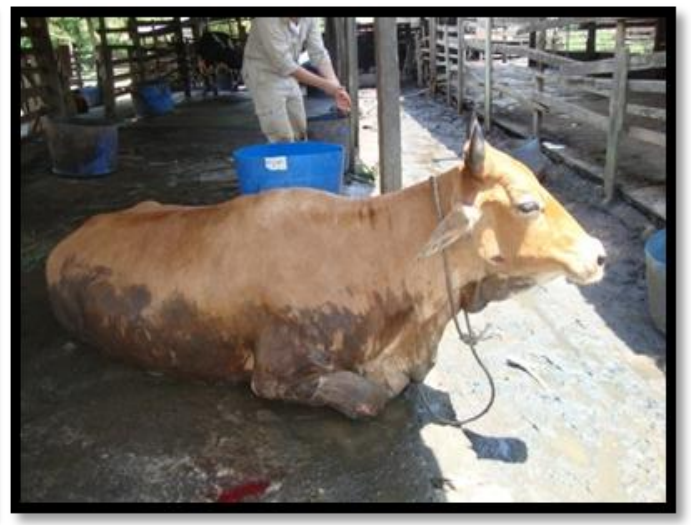

Fig 2: Immediate Recovery after instituting the treatment.

The cow immediately recovered after the drug administration (Fig. 2), hence the prognosis was good.

\section{Discussion And Conclusion}

Milk fever (Parturient paresis) is a disease of considerable importance for dairy cow welfare and economy. Although treatment with intravenous infusion of calcium salt solutions cure most clinical cases of hypocalcaemia, such cows are later more susceptible to other metabolic and infectious diseases $[9,10]$. In many studies, several predisposing factors have been suggested [1,2]. In many countries, high priority has been given in detail to prevent milk fever. In addition, it has been proposed that a specific control program is relevant when the incidence of milk fever increases above $10 \%$ among high-risk cows [8]. Several milk fever control principles and control factors have been described in the database. Of these, oral drenching around calving with a supplement of easily absorbed calcium comes first, followed by feeding of acidifying rations by anionic salt supplementation during the last weeks of pregnancy [5]. Feeding low calcium rations during the last weeks of pregnancy and pre-partum administration of vitamin $\mathrm{D}$, were also among the most recommended measures. In our case, we encountered a stage two milk fever, which was typified by sternal recumbency and curving of the neck to the side. Stage one and two milk fever can be effectively treated by intravenous administration of calcium salts. However, stage 3 milk fever is quite difficult to manage especially when muscle paralysis has ensured $[5,8]$.

\section{Conclusion}

Dietary deficiencies as a result of poor ration formulation is the most probable cause of milk fever in this case. Therefore, farmers should be enlightened about proper ration formulations and provision of mineral supplements to their dairy cows.

\section{Acknowledgment}

The authors would like to thank Mohd Jefri Norsidin and the staff of large animal unit, University Veterinary Hospital, University Putra Malaysia for their technical support.

\section{CONFLICT OF INTEREST}

The authors declare that they have no conflict of interest. 


\section{References}

[1]. Charbonneau E, Pellerin D, and Oetzel GR (2006). Impact of lowering dietary cation-anion difference in non lactating dairy cows: A meta-analysis., J. Dairy Sci. 89:537-548.

[2]. Lean I J, De-Garis P J, McNeil DM and Block E (2006). Hypocalcemia in dairy cows: Meta-analysis and dietary cation anion difference theory revisited., J. Dairy Sci. 89:669-684.

[3]. Horst RL, Goff JP, Reinhardt TA and Buxton DR (1997). Strategies for Preventing Milk Fever in Dairy Cattle., J. Dairy Sci. 80: 1269-1280.

[4]. Roche JR, and Berry DP (2006). Periparturient Climatic, Animal and Management factors influencing the Incidence of Milk Fever in Grazing System., J. Dairy Sci. 89:2775-2783.

[5]. Hutjens MF, and Aalseth EP (2005). Caring for transition cows. Hoards dairyman Books. Illustrated. Pp. 17-21.

[6]. DeGaris PJ and Lean IJ (2009). Milk Fever in Dairy Cows: A Review of Pathophysiolgy and Control Principles., The Vet. J. 176: 58-69.

[7]. Anteneh S, Guadu T, Fentahun T and Chanie M (2012). Incidence of Milk Fever on Dairy Cows and its Risk Factors in Gondar Town, Northwest Ethiopia. Global Veterianaria., 9 (6): 659-662.

[8]. Allenstein LC (1993). Herd health. In: Hoards' dairyman. Illustrated. Hoards dairyman Books, pp. 56-58

[9]. Curtis CR, Erb HN, Sniffen CJ, Smith RD, Powers PA, Smith MC, White ME, Hillman RB, and Pearson EJ (1983). Association of parturient hypocalcaemia with eight periparturient disorders in Holstein cows., J. Am. Vet. Med. Assoc., 183, 559-561.

[10]. Curtis CR, Erb HN, Sniffen CJ, and Smith RD (1984). Epidemiology of parturient paresis: Predisposing factors with emphasis on dry cow feeding and management., J. Dairy Sci. 67, 817-825. 